in the distance separating each pair of stars, a value of the constant of aberration, and a second part of the work was to make a comparison of the measured and computed distances, which would give the corrections to be applied to the refraction tables. A series of subsidiary investigations, the results of which are given on page 203 , was also completed. The result of the whole investigation furnishes as a definite result : Constant of Aberration $=20^{\prime \prime} \cdot 443 \pm \mathrm{O}^{\prime \prime} \cdot$ oro, which differs only very slightly from the commoniy accepted value obtained by Struve, and this within its own limit of probable error. The volume is accompanied by some excellent illustrations of the instrument and the novel dome which protects it. The second part of this volume contains the observations of the right ascensions of the stars observed with the prism apparatus made by Mr. Albert S. Flint.

New Feature on Mars. - A telegram from Kiel announces the observation of a bright prominence on the terminator of the planet, by Messrs. Hussey and Holden, at the Lick Observatory on Wednesday last, August 27. The planet is well situated for observation at midnight, being at present some five or six degrees north of $\alpha$ Tauri.

\section{THE ECLIPSE AT BODÖ AND NORTH FINLAND.}

$W^{E}$ give this week a reproduction of the drawing of the corona made near Bodö, which accompanied Dr. Brester's letter in our last issue (p. 390).

Further particulars have been received concerning the doings of the Russian Expedition under Baron Kaulbars, which observed in Russian Finland. There was an unusually large develop-

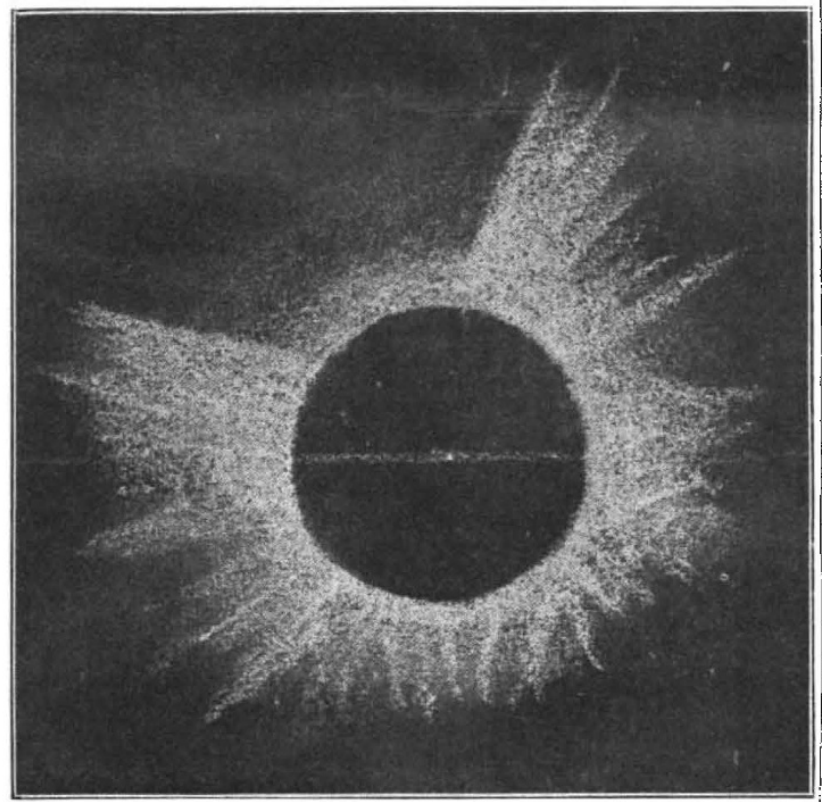

Dr. Brester's drawing of the Corona.

ment of the corona, the extensive and often oblique rays of which surrounded the dark disc of the moon. One of these rays reached a length double that of the sun's diameter. Some of the rays crossed each other, and Baron Kaulbars writes to the St. Petersburger Zeitung " that the remarkable proportions of the corona coincide with the opinion according to which this phenomenon is only very little developed with a minimum of sun-spots, for he had been able to see only very insignificant spots on the sun at rare moments during observations extending over several weeks."

Other expeditions to the Maritime Province of the Amur appear to have been very successful.

NO. I 401 , VOL. 54]

\section{ON THE RONTGEN RAYS. ${ }^{1}$}

WHO would have dreamt at the last annual meeting of the Victoria Institute, that before a year was out, we should be able to see on a screen, to receive on a photographic plate, which is afterwards developed, the skeleton, or a portion of the skeleton of a living man, or at least a living child? And as the modes of exciting these rays improve, we shall probably go on, step by step-indeed already, I believe, the whole body of a full grown man has been penetrated by these rays, the discovery of which we owe to Dr. Röntgen.

I feel some diffidence in bringing this subject before you, because I have never, myself, made experiments with the Röntgen rays. Nevertheless I have read a good deal about them, following what others have done, more especially where it connected itself with the subject of light, to which I have paid a good deal of attention. So I cannot but have a tolerably definite idea in my own mind as to the nature of these Röntgen rays which has been a matter in dispute and, I may say, is still in dispute, although I think opinions are generally coming round to that which I will bring before you in the end.

Now before I go to the Röntgen rays direct, $\mathbf{I}$ must touch on previous work which gradually led up to them.

For a very long time it has been known that an electric discharge passes more readily through tolerably rarefied air, than through air of greater density, and so with other gases. If we have a longish closed tube, provided with electrodes at the ends by means of platinum wires passing through the glass, if the air be tolerably exhausted from it, an electric discharge passes, comparatively speaking, freely through it, forming a beautiful skein of light, if I may so speak, and under certain circumstances that skein of light is divided into strata in a very remarkable manner. These strata fill the greater part of the tube from the positive electrode, or anode, as it is called, till we get nearly, but not quite, to the negative electrode, or kathode. There is a dark space separating the end of the positive discharge which, as I said, under suitable conditions and sufficiently high exhaustion, shows stratification, from a blue glow enveloping the negative electrode or part of it. The luminosity about the kathode is somewhat indefinitely bounded on the side of the stratification.

When, however, the exhaustion is carried still further, at the same time the strata become wider apart, and the luminosity recedes from the kathode and expands, forming a sort of glowing halo much more sharply defined on the inside than the outside ; in that respect resembling the ordinary luminous halo-not the corona-occasionally seen round the moon. We have here, then, these two dark spaces, one outside the halo, where the luminosity gradually fades off, and another dark space on the inside, where the luminosity is more sharply defined, and which reaches to the negative electrode.

Now it is the phenomena in connection with this second dark space that I have more particularly to bring before you. As the exhaustion is rendered higher and higher, the inner dark space gets wider and wider until at a sufficiently high exhaustion it fills the whole tube or bulb. Mr. Crookes has worked more especially at this subject, and, indeed, the tubes which are now used for the production of the Röntgen rays, are generally called "Crookes tubes." I have seen in some of the foreign periodicals the word "Crookes" used to signify one of these tubes. Mr. Crookes' researches in very high vacua led him up to that most remarkable instrument, the radiometer, the nature of which led us to form clearer conceptions, than we had hitherto done, of the nature of the motion of molecules in gas; or rather, when the theory of the radiometer was made out, presented us, as I may say, with a visible exhibition of the thing in actual working.

Now these researches, which led Mr. Crookes to improve his vacuum, naturally. led him to examine the electrical phenomena produced by excessively high vacua.

I have said that it was with the second or inner dark space that $I$ had chiefly to do. When the exhaustion is sufficient, that fills the whole tube.

Now what takes place in this dark space? Suppose we interpose a screen, such as a plate of mica with a hole in it. A portion of the discharge from the negative electrode goes through that hole and continues onwards in a straight course until it reaches the wall of the tube. When it reaches the wall

1 An extract from the Annual Address to the Victoria Institute, by Sir G. G. Stokes, F.kS., the President. 
of the tube (I will suppose the tube, as it is called, to be made of German glass) it produces a greenish yellow fluorescence, or phosphorescence of very brief duration. I need hardly say that if you do not limit what comes from the negative electrode by the screen with a hole in it, you get a broader beam which affects the glass wall over a larger space.

Now what is it that proceeds from the negative electrode towards the glass, and, when it gets there, produces this phosphorescence? Is it light, or is it matter?

One remarkable circumstance connected with this something is, that you can deflect it in its course by a magnet. If you present a magnet to a ray of light it does not deflect it at all ; but this something is easily deflected by a magnet, even by a tolerably weak magnet. Mr. Crookes found that in addition to that property, if this discharge of a something fell upon one side of a very light fan, formed of thin, split mica, and delicately mounted so as to enable it to spin readily, it sent it spinning round; and he believed that the nature of that which we have here to do with is, that it is a stream of molecules. Nobody, I suppose, denies that there is matter propelled; but there has been a considerable difference of opinion as to whether the matte propelled is of the essence of the phenomenon, or whether it is something merely accidental. Mr. Crookes held that it was of the essence of the phenomenon, and that we had here, really, a stream of molecules, and I must say, for my own part, I believe he was right. But some foreign men of science hold that the projection of matter is altogether a secondary phenomenon, and that what comes through this small hole is really only a process which goes on in the ether-something so far of the nature of light, but yet differing from ordinary light most markedly in the property of being deflected by a magnet. To illustrate what I mean by saying something secondary, Prof. Wiedemann, who holds the opinion that it is of the nature of light, or a process going on in the ether, imagines that the projection of matter has no more to do with the phenomenon than the path of a cannon ball has to do with your hearing the sound of the cannon. I think, myself, that it has a great deal more to do with it than that. However, I will leave that matter for the present, to pass on to some researches which led up to the remarkable discovery by Dr. Röntgen.

In Germany, Prof. Lenard made a very remarkable series of experiments in what the Germans call, and what we may call, the kathodic rays, and which he believed to be actual rays, and not streams of molecules sent from the kathode. In order to produce these rays, as I will call them, you want a very high vacuum. If, however, you make your vacuum too high and too nearly perfect, you cannot get the electric discharge to pass through it. A perfect vacuum appears to be a non-conductor, and if you attempted to make the electric discharge pass through it, it would go, by preference, on the outside from one electrode to the other, so that you cannot work directly with anything too nearly approach. ing to a perfect vacuum. But it is a very remarkable thing, though Lenard, I believe, was not the first to discover it, but Hittorff, that these kathodic rays pass or appear to pass through a plate of aluminium which is perfectly impervious to light, or even to the ultra-violet rays, which we know by their effects, though we do not see them directly; so that you may have these kathodic rays at one side and something of the same kind at the other. Lenard constructed an apparatus commencing with a Crookes tube, in which there was very high, though not too high, exhaustion, with a kathode which was either flat or cup-shaped at one end, and opposite to that, in the part where the kathodic rays would strike the glass if it were there, instead of glass it was closed by a thin plate of aluminium foil, so thin that it would support the atmospheric pressure although it was impervious to air. But as a continuation of that tube he had another tube, which was also capable of exhaustion. The two tubes had glass tubes leading from them to the same air-pump. There was communication with the air-pump and communication between the two tubes, and you could exhaust them together, and the pressure would be so far reduced that the aluminium plate was strong enough to sustain the reduced pressure. They were both exhausted together until a suitable exhaustion was produced for the production of the kathodic rays in the first tube, and then the connection between the two tubes was intercepted, and the exhaustion of the second tube, which was kept connected with the air-pump, was continued for several days, until, as near as he could get it, there was nothing at all, in the way of gas, left in it. What was the result? In the first tube the kathodic rays were produced by the electric discharge. They fell on the aluminium foil at the end, and then there was a continuation of kathodic rays in the highly exhausted tube-the vacuum tube I will call it-and these went on as if they had been rays of light. They were deflected by the magnet just like the original kathodic rays.

Now at first sight that looks very much as if you had to deal with actual rays, which passed through the aluminium foil, just as rays of light would pass through a plate of glass. But I think the real explanation of it is altogether different. I believe it to be of this nature. First I will use rather a gross illustration, in order that you may the better apprehend the nature of the other explanation that I am about to bring before you. Suppose that I have a row of ivory balls in contact, such as billiard balls, and that another similar ball strikes the first of these. The result is that the last of the balls is sent off, and the striking ball and the intermediate balls remain approximately at rest. Now it is conceivable that something analogous to that may take place as regards these so-called kathodic rays, supposing they are not rays at all, but streams of molecules. It is conceivable that the molecules proceeding from the kathode or negative electrode of the first tube, be they of residual gas, or aluminium, or platinum, might fall upon the thin aluminium plate which forms a wal between the two tubes, separating the one from the other, and that that would give rise to molecular discharge in the second space, although the actual moving molecules never passed through the wall. As I say that is a rough illustrationrather a gross and material illustration-to enable you to understand more clearly the view I have to bring before you.

I have said that the so-called kathodic rays are easily deflected by a magnet. Now we know from other experiments that if a body sufficiently charged with electricity is in rapid motion, and that motion takes place in a magnetic field, the body tends to be deflected. This looks, therefore, very much as if these kathodic rays are actually streams of molecules, which being highly charged electrically, and of almost inconceivable minuteness, would be deflected by a slight magnetic force. Now, if these highly-charged molecules come to strike on the aluminium wall which separates the two tubes (which are end to end) from one another, it may be that an electrical action goes on which resembles very much what electrolysis is supposed to be according to the views of Grotthuss. I shall not have time to enter into an explanation of that now, for it would lead me too far from the subject; but several present will no doubt understand what I mean when I refer to the views of Grotthuss. The molecules then impinge on the wall, and give rise to a projection of molecules from the second side of the wall, but the latter are not the same molecules which impinged on the first side of it. Whether the molecules projected in the second tube come from a very minute quantity of residual gas, or whether they are derived from the aluminium wall itself, from which they are torn, as it were, does not signify for my purpose. We have here, you see, a conceivable mode of emitting these socalled rays in this way, simulating the transmission of a ray of light through a plate of glass, though it is no ray at all that we are dealing with. I confess I think that that is the true view of the action which takes place. But Lenard himself believed that the kathodic rays were, as he said, processes in the ether. By means of the first tube used alone, as was done in the first instance, but closed with a "window" of somewhat thicker aluminium foil, so as to sustain the atmospheric pressure, he was able to receive the kathodic rays which came from the second surface of the aluminium foil in air, where he could examine them at pleasure, using for their detection sometimes a phosphorescent or fluorescent screen, sometimes a photographic plate. He found that under these conditions they were quickly deflected from their original direction and dispersed, so that they could not be traced far, just like rays of light in a turbid medium, such as water to which a little milk has been added ; whereas in a subsequent series of experiments, to which reference has already been made, in which the kathodic rays were received into a second tube, the dispersion became less and less as the exhaustion proceeded, until at the highest attainable approach to a perfect vacuum the dispersion almost disappeared, and the rays were traced right onwards for a metre and more, and that, without being enlarged by diffraction, as would be the case with rays of light.

Lenard mentioned incidentally that these kathodic rays, as he supposed they were, were able to pass through the hand even. Ife missed the discovery of the $\mathrm{X}$ rays because he had,

NO. I 40 I, VOL. 54] 
I may say, the kathodic rays too much in his head, and attributed the whole effect on either side of the wall to the kathodic rays. Really the effect is due in part to the kathodic rays, and in part to the Röntgen rays, the existence of which he was not aware of. They cannot be distinguished merely by their effect on a fluorescent screen or on a photographic plate, since both these recipients are affected by the rays of both kinds.

Such was the state of things when Röntgen made his remarkable discovery. According to an account which $I$ saw in one of the newspapers (we cannot vouch for the truth of everything we see in the newspapers), the discovery was made in the first instance accidentally. I cannot give you more authentic information than that, but he had been working with a Crookes tube and he observed that a photographic plate, enclosed in the usual case in which these plates are enclosed when you want to protect them from light, showed on development certain markings an it ; so he put the whole apparatus as it had been, with a photographic plate in its case in the same position as before, and the thing was repeated. That is according to the account in the newspapers. A very remarkable discovery was the result. He found that rays were capable of coming out of some part of a Crookes tube which had the remarkable property of passing through substances that are opaque to ordinary light, and opaque even to the ultra-violet with which we were previously acquainted. They pass freely through black paper, through cork, wood, or even through the flesh of the hand, though less freely through the bones, so that by simply laying his hand upon the case containing the photographic plate, he actually got a photograph of the bones of his hand.

Well, what is the nature of these rays and from whence do they come? As Röntgen said in his original paper, a slight examination shows that they have their origin in the part of the Crookes tube opposite to the kathode, and which is rendered phosphorescent by the discharge from the kathode.

The rays, however, which come from this part of the tube, and which appear to have their origin there, differ utterly in some respects from the so-called kathodic rays. If you isolate a portion of them, you find that a magnet has no action upon them; unlike the kathodic rays, they proceed onwards without deflection, just as if the magnet were not there. Like light they proceed in a straight course, but these rays are able to pass through a variety of substances that are opaque to ordinary light, while on the other hand they are stopped by other substances which let light freely through. That, however, does not prove that they are not of the nature of light. You may have, suppose, a red glass which is opaque to green rays, bat lets red rays through very freely, so that as regards merely the fact of the X rays being stopped by substances transparent to light, while they pass more or less freely through other substances which are quite opaque to ordinary light, that establishes no greater distinction than exists between green and red light. Are they then of the same nature as light?

The $\mathrm{X}$ rays have some very remarkable properties by which they appear at first sight to differ in toto from ordinary light. They pass with either no refraction, or excessively small refraction, through prism-shaped bodies, which we know rays of light do not. They suffer hardly any, if any, regular reflection, unless perhaps at a grazing incidence.

Röntgen himself, in his original paper, dwelt on these peculiarities of the new rays. He formed a prism of aluminium, with which he attempted to obtain deviation of the new rays, but the experiment showed that if there were any deviation at all, at any rate the refractive index could not exceed $\mathbf{I} \cdot 05$. He speaks of the rays not being apparently capable of regular reflection, but he brought forward experiments which show that in a certain sense they appear to be capable of reflection.

A photographic plate with the sensitive surface downwards was placed in its case under a Crookes tube, and immediately under the plate, and inside the case, were placed portions of different kinds of metal, which would be capable of reflecting back the rays on to the sensitive surface, if they admitted of reflection; and it was found that the plate was much more darkened over certain of those metals than where the metal did not exist. There was very little darkening over aluminium, and a great deal of darkening comparatively over platinum. This indicated that some effect was produced, though the greater part of it is not one of regular reflection. He conceived the effect to be one of reflection such as you might have from a turbid medium.

$$
\text { NO. I } 4 \text { O I, VOL. } 54]
$$

There is, however, another mode of explanation which seems worth considering, viz. that the köntgen rays, falling upon the metal, throw the molecules into a state of vibration, which they communicate to the ether, by a sort of phosphorescence or fluorescence of X light; so that the rays which come from the molecules, though perhaps not of exactly the same nature as the $\mathrm{X}$ rays that fell upon them, still have enough of the " $\mathrm{X}$ " quality about them, whatever that is, to enable them to get through objects which are opaque to ordinary light.

Lord Blythswood, who has worked a great deal with the Röntgen rays, has written a paper, which was communicated to the Royal Society by Lord Kelvin, in which he establishes a minute regular reflection of those rays from speculum metal at an angle of about $45^{\circ}$. Two plane specula were placed side by side so as to receive at that angle the $\mathrm{X}$ rays coming from a Crookes tube, and a duly protected photographic plate was placed in such a position as to receive the regularly reflected rays if there should be any. The developed plate appeared to show a slight indication of the junction between the mirrors; and that the appearance was not illusory was shown by Lord Kelvin, who made measurements on the image and compared the results with what they ought to be on the supposition of a regular reflection. The indication was so faint that I could not myself perceive it (I have not seen the negative, but only positive copies), but Lord Blythswood has given me some positive copies of a negative which he subsequently obtained by reflection from a concave speculum at a small angle of incidence, and which show for certain a minute regular reflection of $\mathrm{X}$ rays, while at the same time they prove that the quantity of $\mathrm{X}$ light returned by regular reflection is extremely small compared with that which comes from the mirror by some different process.

Now there is another remarkable property of these rays, or absence of property, if you like so to call it. Rays of light, as we know, admit of diffraction. If you pass light from a luminous point through a very small slit, or a small hole, the riband, or the beam of light at the other side, does not follow merely the geometrical projection of the slit or hole as seen from the source of light, but is more or less wiuened, and certain alternations of illumination are visible, a pheisomenon referable to interferences which $I$ have not time to go into. How do these $X$ rays behave under such conditions? It is a very remarkable thing that they do not show these enlargements or exhibit any sign of interference.

The last number of the Comptes rendus contains a paper by M. Gouy in continuation of a former paper, but describing experiments carried out in a still more elaborate manner, which proves the truth of this to a very high degree of strictness. He makes out that if these $\mathrm{X}$ rays are periodical, the wave-length cannot well be more than the one-hundredth part of the wave-length of green light, indicating an enormously high degree of frequency.

Now, if we assume that the $\mathrm{X}$ rays, like rays of light, and unlike the kathodic rays, are a disturbance propagated in the ether, ponderable matter being concerned only in their origination, not in their propagation, the question arises, What is the relation between the direction of vibration and the direction of propagation? Are the vibrations normal or transversal? We know that the vibrations of the air which constitute sound take place in a to and fro direction, or are what is called normal-that is, perpendicular to the waves of sound. We have the fullest evidence that the vibrations of the ether which constitute light take place in directions perpendicular to that of propagation, or are what is called transversal. To which category do the vibrations belong which constitute the $\mathrm{X}$ rays?

If we could obtain polarisation, or even partial polarisation, of the $\mathrm{X}$ rays, that would settle the question, and prove that they are due to transversal vibrations. But most of those who have attempted to obtain indications of their polarisation have failed. This, however, does not prove that the vibrations are normal, for the peculiar properties of the $\mathrm{X}$ rays shut us out-or, at least, almost completely shut us out-from the ordinary means of obtaining polarisation. There is, however, one paper in the Comptes rendus, by Prince Galitzine and $\mathrm{M}$. de Karnojitsky, in which the authors profess to have obtained by a special method undoubted indications of polarisation. No reasonable doubt can remain as to the abstract capacity of these rays for polarisation after what has been done by another physicist. I wish I had time to go into the experiments that 
have been made by M. H. Becquerel in the direction of polarisation; but I have already kept you too long. He had more particularly studied a very remarkable phenomenon, viz. that certain phosphorescent bodies--such as sulphide of calcium, for instance, and salts of uranium-on exposure to ordinary sunlight give out rays of some kind which pass through bodies opaque to light, and are able to affect a photographic plate beneath them. So far these agree in their properties with the $\mathrm{X}$ rays which are obtained from a Crookes tube, which they far more closely resemble than they do rays of ordinary light; but the rays thus obtained were found by Becquerel to admit of polarisation by means of tourmalines in a manner altogether unmistakable. I think, therefore, that we may take it as established that the Röntgen rays are due to some kind of transversal disturbance propagated in the ether.

The non-exhibition of the ordinary phenomena of diffraction and interference is explicable on the supposition that the vibrations in the $X$ rays are of an excessively high order of frequency. I am not sure that a different sort of explanation might not, perhaps, be possible which I have in my mind, though I have not matured it ; but, save the possibility of that, one is led to regard them as consisting of transverse vibrations of excessively high frequency. This opens out some points of considerable interest in the theory of light; but I am afraid it would keep you too long if I were to attempt to go further into this matter. I will merely remark that, taking the way in which these rays are most commonly produced, viz. as coming from a point where the kathodic discharge in the Crookes tube falls on the opposite wall, we may understand how it is that vibrations of excessively unusual frequency may be produced. These highly charged molecules, charged with electricity, coming suddenly against the wall, may produce vibrations of a degree of frequency which we are not at all prepared for ; but I see by the clock that I must not detain you any longer on speculations.

Postscript.-This "different sort of explanation" is one between which and the supposition of periodic vibrations of excessively high frequency my mind has for a long time oscillated. In the above lecture I gave the preference to the latter; but subsequent reflection leads me strongly to incline to the former. I hope before long to develop fully these views elsewhere; meanwhile, suffice it to say that I am disposed to regard the disturbance as non-periodic, though having certain features in common with a periodic disturbance of excessively high frequency.

\section{THE ICE VOYAGE OF THE "FRAM."}

$D^{R}$. NANSEN has communicated to the Daily Chronicle, by telegraph from Tromsö, some interesting details given by Captain Sverdrup, with reference to his voyage in the Fram. The marvellous way in which the Fram withstood the icepressure, and the methods employed to free the ship from the ice, is an object-lesson for future Arctic explorers. The telegram is abridged below.

On March 14, 1895, Nansen and Johansen left us. During the first month after their departure, the ice was very quiet and the drift inconsiderable. Towards the end of April the drift, however, improved, and we were carried westwards. On July 26 the Fram was in $84^{\circ} 5^{\prime} \mathrm{N}$, and $73^{\circ} \mathrm{E}$. long. There was during this time much ice-pressure, but it never reached the ship. Then we had winds from south-west and west, which during the summer drifted the Fram backwards towards the east and north-east. It was not before October that the favourable drift recommenced, and during the autumn and winter, and especially during January and the first part of February 1896 , our drift was better than ever.

On October 16, 1895, the Fram had reached the highest latitude observed, viz. $85^{\circ} \cdot 57^{\prime} \mathrm{N}$., and $66^{\circ} \mathrm{E}$. long. In the middle of February we were on $84^{\circ} 20^{\prime} \mathrm{N}$., and $23^{\circ} \mathrm{E}$., but here the drift closed until May, when we were again carried south. wards. On July 19 we had reached $83^{\circ} 14^{\prime} \mathrm{N}$., and $14^{\circ} \mathrm{E}$. long.

There we got the Fram out of the grasp of the ice by blasting with gun-cotton and powder, and began to force our way southwards. During the whole drift in the ice the Fram was exposed to constant and violent pressures. None of these were, however, so dangerous as that which we had at New Year before Nansen left us. Immediately after his departure we were

NO. I 4OI, VOL. 54] occupied in removing the huge mass, of ice which on that occasion was pressed against the Fram's sides. At the end of March, just as the last portion of this ice was being removed, the ice suddenly cracked in all directions round the ship, and a broad water-lane was formed, which came within a few feet of the Fram's stern. Strong pressure very soon began along this crack, and the ice was so much broken up that the Fram at the end of July lay close to open water. A single mine was sufficient to free the ship from the ice.

As this mine was exploded, the Fram glided from the ice into the water like a ship being launched from her ways, but with a noise like thunder, the crew cheering loudly as she struck the water. Having been brought into a safe harbour by warping and sawing the ice, she was again, in August, frozen in. The ice-pressures were, during this year, of no great importance in comparison with the pressures this last summer.

During one week in June this summer (1896), at the height of the spring tides, the Fram was regularly exposed to violent pressures caused by the changing tide-currents. She was then once or twice a day lifted 6 to 9 feet, and her bottom could be seen resting on the ice. On all these occasions the Fram proved to be the very ship for ice. She was quietly lifted, and not a noise or a crack was heard from her timbers. The men on board were not disturbed in their slumber, even when the pressure was at its highest, and we awoke in the morning in ignorance of what had happened during the night. It was not before we came on deck that we observed how high we were lifted above the ice.

The temperature of the air was pretty even during our whole voyage, and did not fall lower than during the first winter. The depth of the sea was during our drift about the same as we had found before Nansen's departure, viz. I 800 to 1900 fathoms. In the temperature of the sea there was also little change, but the warm layer of Gulf Stream water under the cold surface-water increased a little in body as we came westwards. Depôts of provisions, boats, kayaks, and all necessary equipment were during our whole drift kept in readiness on the ice in the neighbourhood of the Fram, in case of fire or other accidents.

The time passed comfortably and peacefully, much in the same way as during the first winters. An easier expedition can hardly be imagined. Our principal work was to take the regular observations, sleep, eat, and drink. Our health was perfect the whole time, and we had no sign of scurvy. When the ice began to slack a little this summer, we worked hard to loosen the Fram from the ice-a difficult task, owing to the huge ice, piled up by pressures, in which our ship was frozen. We succeeded, after some days' hard work, by blasting, using mines of up to IOO lb. of powder. Guncotton proved the best.

From July ig to August 13 we forced our way southwards through I 50 miles of close ice. The ice was, as a rule, very high, and the floes were so extensive that we could not see all of them, even with telescopes. It often seemed to be hopeless, and if the Fram had not been such a superior ship for ice-navigation it would have been quite useless to try to force our way through ice-masses of such a description. It was by steam and warping that we broke our way through foot by foot, and where the ice was too bad for this it was forced by blasting.

We came out of the ice on August 13-the same day on which Nansen and Johansen arrived at Vardö in Norway.

\section{UNIVERSITY AND EDUCATIONAL} INTELLIGENCE.

THE Lords of the Committee of Council on Education have appointed Mr. A. J. R. Trendell, C.M.G., to be AssistantSecretary of the Department of Science and Art, in succession to Mr. G. F. Duncombe, retired. Mr. Edward Belshaw succeeds Mr. Trendell as the Chief Clerk.

THE retirement of Prof. Erismann from the chair of Hygiene in the University of Moscow, is announced.

Colonel Pennycuick, late R. E., has been appointed President of the Engineering College, Cooper's Hill, in the place of General Sir Alexander Taylor, retired.

THE following announcements have been recently made:Dr. Burney Yeo, to be Professor of Medicine, and Dr. Curnow, to be Professor of Clinical Medicine at King's College, London.

A scheme for a Central Technical College in Liverpool, for which the plans have already been accepted, now awaits the 